SECONDARY BATTERIES.-J. Rousse.-In order to accumulate electricity for the production of light or motive power, the author has arranged secondary batteries, which differ from those of M. G. Plant. At the negative pole he uses a sheet of palladium, which, during the electrolysis, absorbs more than 900 times its volume of hydrogen. At the positive pole he uses a sheet of lead. The electrolysed liquid is sulphuric acid at $1-10 t h$. This element is very powerful, even when of small dimensions. Another secondary element which has also given good results, is formed at the negative pole of a slender plate of sheet-iron. This plate absorbs more than 200 times its volume of hydrogen when electrolysed in a solution of ammonium sulphate. The positive pole is formed of a plate of lead, pure or covered with a stuatum of litharge, or pure oixide, or all these substances mixed. These metallic plates are inmersed in a solution containing 50 per cent of ammonium sulphate. Another arrangement is at the negative pole, sheet-iron ; at the positive pole a cylinder of ferro-manganese. The electrolysed liquid contains 40 per cent ammonium sulphate.

CONSTIUTION OFTHE MILKY WAY,-When the milky way is regarded with an indifferent eye, it seems that its brightness is the same in all parts. But it is quite otherwise when the relative luminuus intensity of its different portions is measured. It is then found that the milky way is composed of a series of luminous plates separated from each other by darker portions. Thirty-three of these nodules have been counted, the centre of which is more brilliant than the borders, and it is stated that they are arranged nearly mathematically along a great circle of the celestial sphere.

\section{AN EXPLANATION.}

\section{To the Editor of "SCIENCE."}

DEAR SIR,-In giving the specific rotatory power in my article "Amylose" in SCIENCE of Oct. Ist this year, I used the expression (a) to designate the specified rotatory power for the teinte de passage since that is the usual ray employed. On the other hand I used (a)j to designate the same property for the yellow ray, meaning by the yellow ray the monochromatic sodium flame.

Since, however. it is the usual custom to designate the "rose-purple" transition tint by (a)j as if it were a yellow ray and the sodium ray by (a) D, I desire to make this explanation of the symbols used. Respectfully,

\section{LAFAYETTE, IND., Non'. 5, I88I.}

\section{W. WILEY.}

OUSFRVATIONS ANU RESHARCHFS ON BLOOD-STAINS. -1).Vitaci-Attention has been recently called to a reaction discovered by Schabein-the blue coloration produced by a mixture of cil of turpentine and alcoholic tincture of the resin of guiacum, on the additionof a little blcod or a very dilute solution of hatmoglobin. It is said that this reaction is preferable to any other, not excepting that founcied on the formation of crystals of hemine and on spectroscopic observation, and that none of the substances capable of s.mu!.ting blood-spots give the same opaque blue color. The author, however, shows that all substances capaijle of acting as cirect or indirect oxidising agents are capable of producing the same reaction.

METEOROLOGICAL REPORT FOR NEIV YORK CITY FOR THE WEEK ENIDING NOV. 12, 1881. Latitude $40^{\circ} 45^{\prime} 58^{\prime \prime} \mathrm{N}$; : Longitude $73^{\circ} 57^{\prime} 58^{\prime \prime} \mathrm{IV} . ;$ feet; by self-recording instruments.

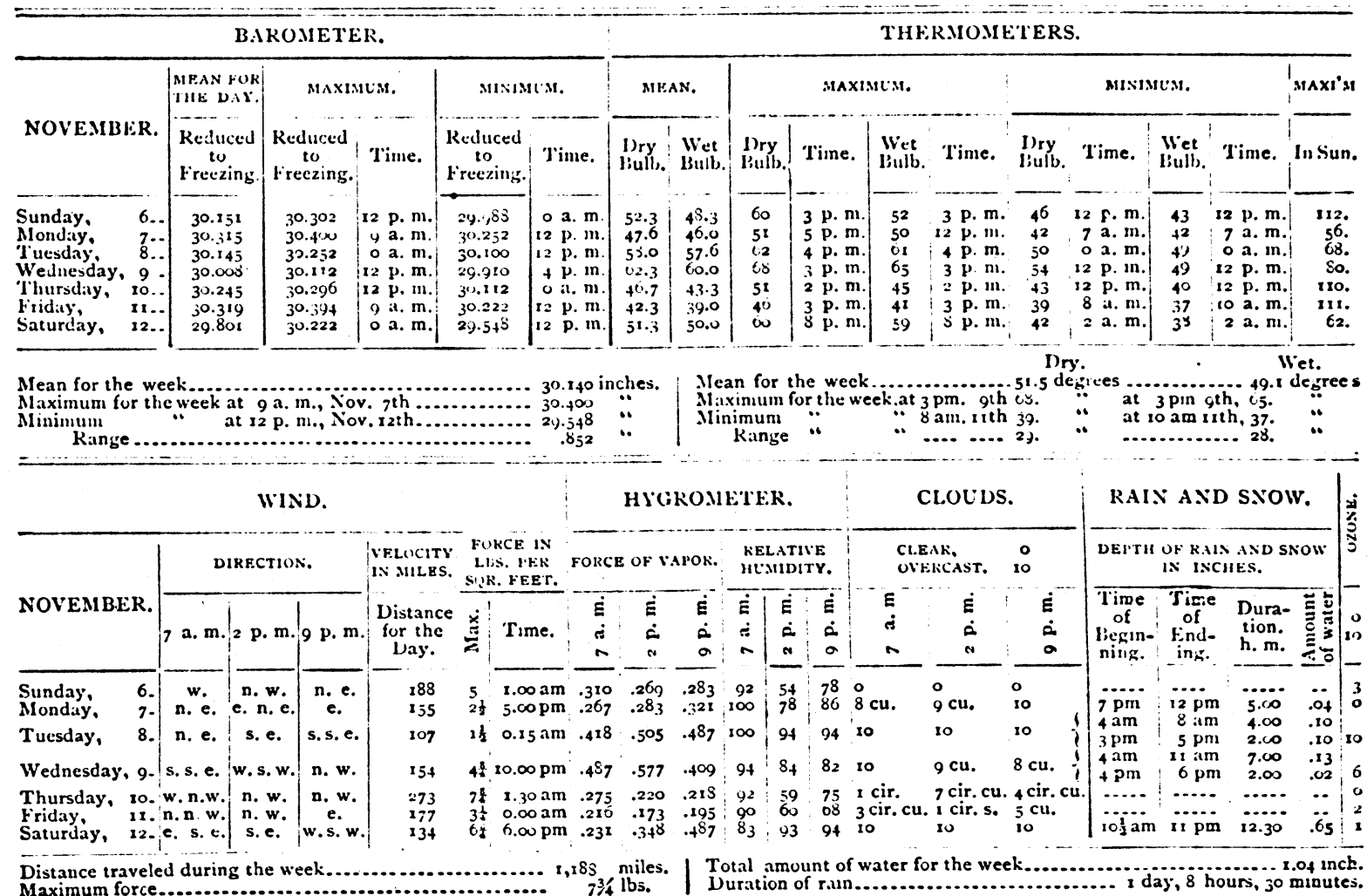

